\title{
Free convection in a square enclosure with a finned plate
}

\author{
Djamel Sadaoui ${ }^{1}$, Adel Sahi ${ }^{1, a}$, Hamici NadjiB $^{1}$, Bachir Meziani ${ }^{2}$ and Tarik Amoura ${ }^{1}$ \\ 1 Laboratoire de Mécanique, Matériaux et Energétique (L2ME), Faculté de Technologie, Université A. Mira de Bejaia, \\ 06000 Bejaia, Algérie \\ 2 Laboratoire de Physique Théorique (LPT), Faculté des Sciences, Université A. Mira de Bejaia, 06000 Bejaia, Algérie
}

Received 28 March 2014, Accepted 14 December 2014

\begin{abstract}
The study goes further to investigate numerically the effect of a finned plate on the heat transfer and fluid flow in a square enclosure with isothermal boundary conditions for a range of the Rayleigh numbers $10^{3}-10^{6}$. The governing equations under Boussinesq approximation are solved in their dimensionless form by means of the finite volume method. Results for the cases computed are presented in terms of streamlines, isotherms and Nusselt numbers and show the condition of the enhancement of heat transfer from the finned plate to the surrounding cavity walls. They reveal that the heat and flow fields are dependent on the Rayleigh number and several geometrical ratio parameters.
\end{abstract}

Key words: Free convection / square enclosure / finned plate / heat transfer / thermal buoyancy

\section{Nomenclature}

\begin{tabular}{|c|c|}
\hline & \\
\hline$A, H_{a}, L_{a}$ & Aspect ratio \\
\hline$g$ & Gravitational acceleration $\left(\mathrm{m} \cdot \mathrm{s}^{-2}\right)$ \\
\hline$H,(h)$ & Width of the enclosure (plate) (m) \\
\hline$k$ & Thermal conductivity $\left(\mathrm{W} \cdot \mathrm{m}^{-1} \cdot \mathrm{K}^{-1}\right)$ \\
\hline$l_{a}$ & Height of the fin $(\mathrm{m})$ \\
\hline$N f$ & Fin number \\
\hline$\overline{N u}$ & Average Nusselt number \\
\hline $\mathbf{p}$ & Dimensionless pressure: $\mathbf{p}=p L^{2} /\left(\rho \nu^{2}\right)$ \\
\hline $\operatorname{Pr}$ & Prandtl number: $\operatorname{Pr}=\nu / \alpha$ \\
\hline $\mathrm{Ra}$ & Rayleigh number: $\mathrm{Ra}=g \beta\left(T_{h}-T_{c}\right) H^{3} / \nu^{2}$ \\
\hline Gr & Grashof number: $\mathrm{Gr}=\mathrm{PrRa}$ \\
\hline $\mathbf{V}_{i}$ & Dimensionless velocity components $\left(V_{i} L / \nu\right)$ \\
\hline $\mathbf{X}_{i}$ & Dimensionless Cartesian coordinate $\left(X_{i} / L\right)$ \\
\hline & Greek symbols \\
\hline$\alpha$ & Thermal diffusivity $\left(\mathrm{m}^{2} \cdot \mathrm{s}^{-1}\right)$ \\
\hline$\beta$ & Thermal expansion coefficient $\left(\mathrm{K}^{-1}\right)$ \\
\hline$\nu$ & Kinematic viscosity $\left(\mathrm{m}^{2} \cdot \mathrm{s}^{-1}\right)$ \\
\hline$\rho$ & Density $\left(\mathrm{kg} \cdot \mathrm{m}^{-3}\right)$ \\
\hline$\theta$ & Dimensionless temperature $\left(T-T_{c}\right) /\left(T_{h}-T_{c}\right)$ \\
\hline$\delta_{i j}$ & Delta Kronecker \\
\hline
\end{tabular}

\section{Introduction}

Convection flow and heat transfer inside different shaped enclosures have been the topic of many research

\footnotetext{
${ }^{a}$ Corresponding author: sahi.adel@hotmail.fr
}

engineering studies. These consist of various engineering applications such as solar collectors, building heating and ventilation and electronic cooling devices. A literature survey related to this topic revealed that numerous investigations are substantially orientated toward the study of concave or triangular enclosures; references [1-8]; give some ideas about fluid flow and thermal characteristics inside cavities with different boundary conditions.

Thereafter, the interest is focused on complex cavities with obstructions, fins or baffles. Buoyancy driven flow and heat transfer through a heated element within a square enclosure subject to various thermal conditions has been described in references [9-15]. In the light of the above literature, it is pointed out that the detection of the transition threshold from steady-state to time-dependent regimes not only is of basic scientific interest, but also has practical significance. Further, the flow and heat transfer patterns near the obstructions are greatly influenced by the shape of their cross-section. Several correlations of the average Nusselt number were proposed as a function of Rayleigh number and geometric ratios.

All the aforementioned works showed that the heat transfer is limited by the enclosure area and several parameters. As a result, the addition of a fin or array of fins to the enclosure surfaces is a suitable technique to improve the overall heat transfer rate between the working fluid and the heat absorbing surfaces. Thorough literature survey revealed that comparatively little work has been reported on natural convection in enclosure with fins attached to its walls [16-21]. These investigations 

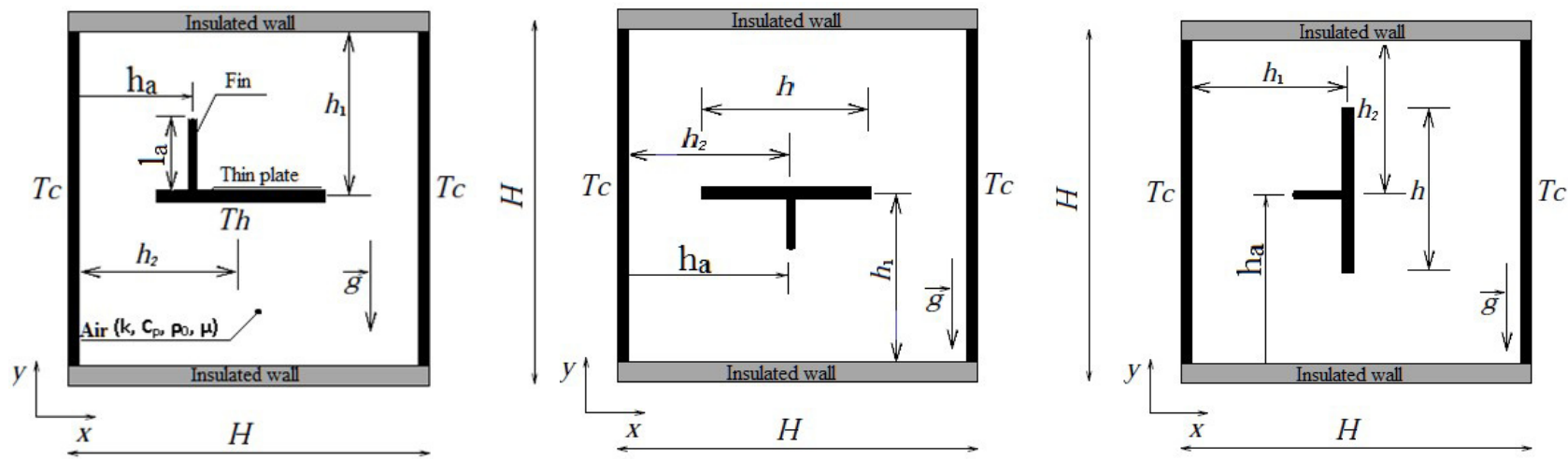

Fig. 1. Computational domain.

are recently motivated by the advance in the electronics technology and the need for reliable and efficient cooling techniques. They namely reveal that the presence of internal fins (baffles) themselves contribute to the total heat transfer and their presence greatly affects thermal performances of such systems.

It should further be started that thin plate shaped elements within enclosures have received considerable attention over the past few decades in view of the numerous potential applications. Reviews on this subject can be found in the publications of Famouri [22], Oztop [23], Tasnim [24], Altac [25], Abdul Hakeem [26,27], Saravanan [28] and Mahmoodi [29]. Thus it turns out that geometric structures (length, location, element shape) as well as the boundary condition alter markedly the basic flow pattern and the heat transfer rate within such cavities.

In summary, previous studies deal with buoyancy driven flow in the surrounding of a heated element within a square cavity. The novelty of this work lies in the combination of a heating element (thin plate) with fins. Hence, the effects of Rayleigh number, plate orientation, fin number and various aspect ratios on the flow field and heat transfer characteristics in the surrounding of the finned plate are discussed, respectively.

\section{Description of the problem}

The considered physical geometry with related parameters and coordinates are shown in Figure 1. The thin finned plate, is supposed to be isothermal at higher temperature than two vertical isothermal walls while top and bottom walls are insulated. For simplicity several parameters are defined in terms of aspect ratios such as: $A=h / H ; A_{1}=h_{1} / H ; A_{2}=h_{2} / H ; H_{a}=h_{a} / H$; $L_{a}=l_{a} / h_{1}$.

\section{Mathematical formulation}

Analysis is applicable to steady, Newtonian laminar incompressible flow. Viscous dissipation and radiation are neglected. Also, constant fluid properties are assumed except for the density which is temperature-dependent. With these assumptions, the dimensionless form of the basic equations under the Boussinesq approximation is written as:

$$
\begin{aligned}
\frac{\partial \mathbf{V}_{i}}{\partial \mathbf{X}_{i}} & =0 \\
\mathbf{V}_{j} \frac{\partial \mathbf{V}_{i}}{\partial \boldsymbol{X}_{j}} & =-\frac{\partial \mathbf{p}}{\partial \mathbf{X}_{j}}+\operatorname{Pr} \frac{\partial^{2} \mathbf{V}_{i}}{\partial \mathbf{X}_{j} \partial \mathbf{X}_{j}}+\operatorname{Gr} \theta \delta_{i 2} \\
\boldsymbol{V}_{j} \frac{\partial \theta}{\partial \mathbf{X}_{j}} & =\frac{1}{\operatorname{Pr}} \frac{\partial^{2} \theta}{\partial \mathbf{X}_{j} \partial \mathbf{X}_{j}}
\end{aligned}
$$

The problem is now to solve Equations (1)-(3), subject to no-slip and impermeable boundary condition on the solid walls. The relevant boundary conditions in the dimensionless form can be stated as follows:

$$
\begin{array}{rrll}
\mathbf{V}_{x}=\mathbf{V}_{y}=0 & \theta=1 & & \text { (inner finned plate) } \\
\mathbf{V}_{x}=\mathbf{V}_{y}=0 & \theta=0 & & \text { (enclosure vertical walls) } \\
\mathbf{V}_{x}=\mathbf{V}_{y}=0 & \nabla \theta=0 & & \text { (enclosure horizontal walls) }
\end{array}
$$

\section{Numerical procedure}

The motion of the fluid governed by the continuity, momentum and energy equations with corresponding boundary conditions is solved numerically by the finite volume method approach. To do so, the domain has been discretized into a finite number of non-overlapped control volumes (Fig. 2). To check the convergence of the sequential iterative solution, normalized residual respectively for the mass, momentum and energy equation is calculated, convergence is obtained when the residual becomes smaller than $10^{-9}$. Extensive validation of the developed code has been carried out by comparing the results with those reported by Oztop et al. [23] on natural convection in a cavity with a thin heated plate. The computations have been performed in terms of mean Nusselt number for various Rayleigh numbers and are shown in Table 1. As shown, excellent agreement has been obtained and the 


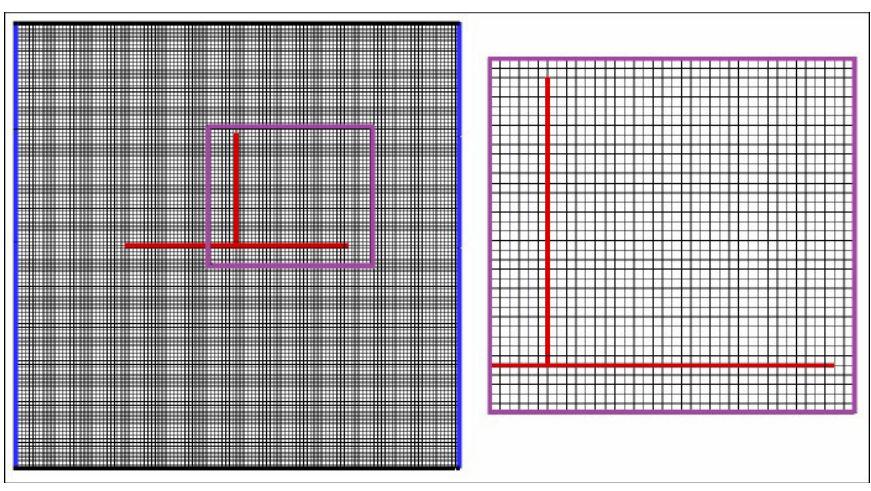

Fig. 2. Detail of the computational grid.

maximum deviation between the results was within $3 \%$, which provides sufficient confidence in the present numerical model to deal with the physical problem.

\section{Discussion and results}

Different scenarios for natural convection in a cavity with a finned plate were explored for ranges of Rayleigh number from $10^{3}$ to $10^{6}$ and different aspect ratio $(A=$ 0.2 to $0.6 ; H_{a}=0.25$ to 0.75 and $L_{a}=0.25$ to 0.75 ) while the Prandtl number is held fixed to $\operatorname{Pr}=0.71$. To allow grid-independent examination and find a proper size of grids, a grid independence test is carried out in this section for the case of $L_{a}=0.5 ; H_{a}=0.5 ; A_{1}=0.5$ and $\mathrm{Ra}=10^{5}$. The numerical procedure has been conducted for different grid resolutions.

The results were checked for grid independence and grid sides change from $20 \times 20$ to $160 \times 160$ according to the aspect ratio of the enclosure. The maximum value of the stream function $\left(\left|\Psi_{\max }\right|\right)$ was used as a sensitivity measure of the accuracy of the solution. As listed in Table 2, various grid size yield results with a maximum deviation less than $1 \%$. Hence considering both the accuracy and the computational costs, most computations reported in this study for a single cell were performed with a multiple grid system of $100 \times 100$. Nevertheless, similar tests were carried out when the number of fins increase, and the grid size was adjusted accordingly.

\subsection{Effects of geometrical aspect ratios on flow pattern}

Figures 3-5, show the effect of several parameters as Rayleigh number, aspect ratios $H_{a}$ and $L_{a}$ on streamlines and temperature contours in the enclosure. The flow within the cavity takes place by virtue of thermal buoyancy which is represented by the Rayleigh number Ra. The flow field is similar to that obtained by Oztop [23], it presents two major cells rotating in opposite directions. As it is predicted, due to linearly heated body, the flow rises up parallel to the vertical axis from the middle portion of the bottom wall and gets blocked at the top adiabatic wall, than flow down along the cooled walls. The fluid motion involves two primary convective cells extending throughout the enclosure with clockwise and anti-clockwise rotations. Whatever the Rayleigh number; the flow field in the left and right sides of the fin is not completely identical for $H_{a} \neq 0.5$ in horizontal case (Figs. 3 and 4 ) and for all configurations in vertical case (Fig. 5). It became symmetric when the fin is positioned at $H_{a}=0.5$ (middle of the plate). Moreover, if we consider the horizontal configurations (Figs. 3 and 4) and low Rayleigh number $\left(\mathrm{Ra} \leq 10^{4}\right)$ it can be seen clearly that each primary cell consists of two co-rotating secondary cells at the top and bottom corners of the enclosure. The displacement of the fin to the left edge of the thin plate $\left(H_{a}=0.25\right)$ reduces the upper left secondary cell while the right one stretches in the horizontal directions (Fig. 3). The opposite phenomenon is observed for horizontal finned plate facing down (HPFD) (Fig. 4). The increasing of the fin height $\left(L_{a}=0.25 ; 0.5\right.$ and 0.75$)$ tends to accentuate the phenomenon observed in previous case. The isotherm plots at low Grashof number $\left(\mathrm{Gr} \leq 10^{4}\right)$ (Fig. 4), are smooth curves which span the entire enclosure; this indicates that the conduction is the dominant heat transfer mechanism in the enclosure. The temperature contours are symmetric with respect to the vertical symmetric line when $H_{a}=0.5$. As seen in Figure 3, further significant increase in the value of Rayleigh number $\left(\mathrm{Ra}=10^{6}\right)$ due to increased temperature gradient causes the recirculation cells to rotate faster especially in the upper part of the cavity with disappearance of the lower secondary cells. For $H_{a}=0.25$ as the height of the fin grows $\left(0.25 \leq L_{a} \leq 0.75\right)$, the left primary cell becomes squeezed by the core of the primary right cell which moves up. Unlike the case $H_{a}=0.25$ in which the isotherms and streamlines are asymmetric it's clearly observed that the flow patterns consist of two similar and symmetric counter rotating cells close to each of the cold walls with respect to the vertical axis of the cavity. As fin height increases $\left(L_{a}=0.25 ; 0.5\right.$ and 0.75$)$ the intensity of the natural convection increases, and each secondary cell is divided into two minor cells located near the top left and right vertical walls.

In the second configuration (Fig. 4), where the horizontal finned plate is facing down (HPFD) the phenomenon is much more complex, however we note the appearance of one or two small cells on the top right and left sides of the plate for $H_{a}=0.25$ and $H_{a}=0.5$, respectively. For relatively high Rayleigh number $\left(\mathrm{Ra}=10^{6}\right)$; the isotherm pattern changes significantly, indicating that the convective mechanism is dominating. The convection increases significantly and becomes stronger. It's accompanied by significant distortion in the temperature contours so that a thermal stratification due to stagnation of flow prevails in the central region surrounding the heated plate. Moreover, the temperature contours are concentrated and compressed toward vertical walls and horizontal thin plate.

Because of the symmetrical geometry $\left(H_{a}=0.5\right)$ and boundary conditions, the isotherms plots are symmetrical 
D. Sadaoui et al.: Mechanics \& Industry 16, 310 (2015)

Table 1. Comparison between present result and Oztop [23].

\begin{tabular}{|c|c|c|c|c|c|c|c|c|c|}
\hline \multicolumn{10}{|c|}{ Average Nusselt: horizontal plate } \\
\hline & \multicolumn{3}{|c|}{$A=0.2$ and $A_{1}=0.5$} & \multicolumn{3}{|c|}{$A=0.4$ and $A_{1}=0.5$} & \multicolumn{3}{|c|}{$A=0.6$ and $A_{1}=0.5$} \\
\hline $\mathrm{Ra}$ & $10^{4}$ & $10^{5}$ & $10^{6}$ & $10^{4}$ & $10^{5}$ & $10^{6}$ & $10^{4}$ & $10^{5}$ & $10^{6}$ \\
\hline Ref. [23] & 1.06 & 1.62 & 2.36 & 1.46 & 2.06 & 3.82 & 2.04 & 2.5 & 5.03 \\
\hline Current work & 1.07 & 1.557 & 2.383 & 1.456 & 1.975 & 3.83 & 2.035 & 2.54 & 5.04 \\
\hline Error $\%$ & 0.943 & 3.08 & 0.84 & 0.68 & 2.47 & 0.26 & 0.24 & 1.6 & 0.19 \\
\hline \multicolumn{10}{|c|}{ Average Nusselt: vertical plate } \\
\hline & \multicolumn{3}{|c|}{$A=0.2$ and $A_{1}=0.5$} & \multicolumn{3}{|c|}{$A=0.4$ and $A_{1}=0.5$} & \multicolumn{3}{|c|}{$A=0.6$ and $A_{1}=0.5$} \\
\hline $\mathrm{Ra}$ & $10^{4}$ & $10^{5}$ & $10^{6}$ & $10^{4}$ & $10^{5}$ & $10^{6}$ & $10^{4}$ & $10^{5}$ & $10^{6}$ \\
\hline Ref. [23] & 1.111 & 1.81 & 3.19 & 1.49 & 2.56 & 5.20 & 1.75 & 3.08 & 6.40 \\
\hline Current work & 1.110 & 1.833 & 3.28 & 1.492 & 2.572 & 5.208 & 1.751 & 3.086 & 6.398 \\
\hline Error \% & 0.09 & 1.1 & 2.82 & 0.13 & 0.46 & 0.15 & 0.05 & 0.19 & 0.03 \\
\hline
\end{tabular}

Table 2. Grid size dependency.

\begin{tabular}{ccccccccc}
\hline \multicolumn{10}{c}{$\mathrm{Ra}=10^{5}$} \\
\hline Grid & $20 \times 20$ & $40 \times 40$ & $60 \times 60$ & $80 \times 80$ & $100 \times 100$ & $120 \times 120$ & $140 \times 140$ & $160 \times 160$ \\
$\left|\Psi_{\text {max }}\right|$ & 0.0318 & 0.0762 & 0.2042 & 0.3678 & 0.4820 & 0.4820 & 0.4820 & 0.4820 \\
\hline
\end{tabular}

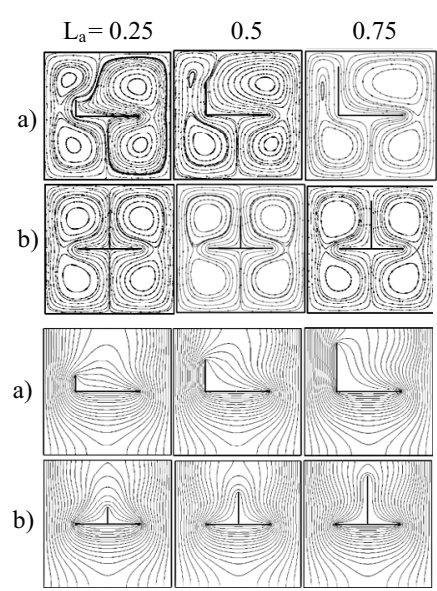

$\mathrm{Ra}=10^{4}$

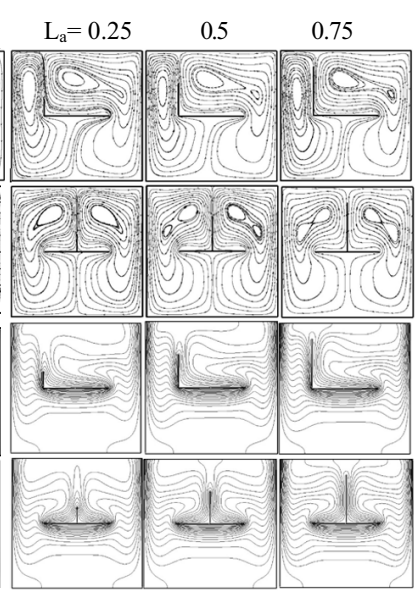

$\mathrm{Ra}=10^{6}$
Fig. 3. Streamlines and isotherms for a horizontal finned plate oriented facing up (HPFU): $\left(A=0.5 ; A_{1}=0.5\right)$ : (a) $H_{a}=$ 0.25 , (b) $H_{a}=0.5$.

about the vertical mid plane and concentrated underneath the hot plate, indicating the presence of large temperature gradient here. It's observed that displacement of the fin to left or right (increasing or decreasing $H_{a}$ ) affects the flow and temperature patterns. Beyond $\mathrm{Ra}=10^{5}$ an isothermal plume appears and moves with the fin location.

Figure 5 illustrates, the effects of both dimensionless fin height $\left(L_{a}\right)$ and position $\left(H_{a}\right)$ on the flow pattern and temperature distribution for $\mathrm{Ra}=10^{4}$ and $\mathrm{Ra}=10^{4}$. At low Rayleigh number $\mathrm{Ra}=10^{4}$, when $H_{a}$ and $L_{a}$ vary between $0.25 \leq H_{a} \leq 0.75$ the convection is weak. Thus, two dominant buoyancy induced vortices prevail in the enclosure, the right as the left one rotate in the clockwise and in

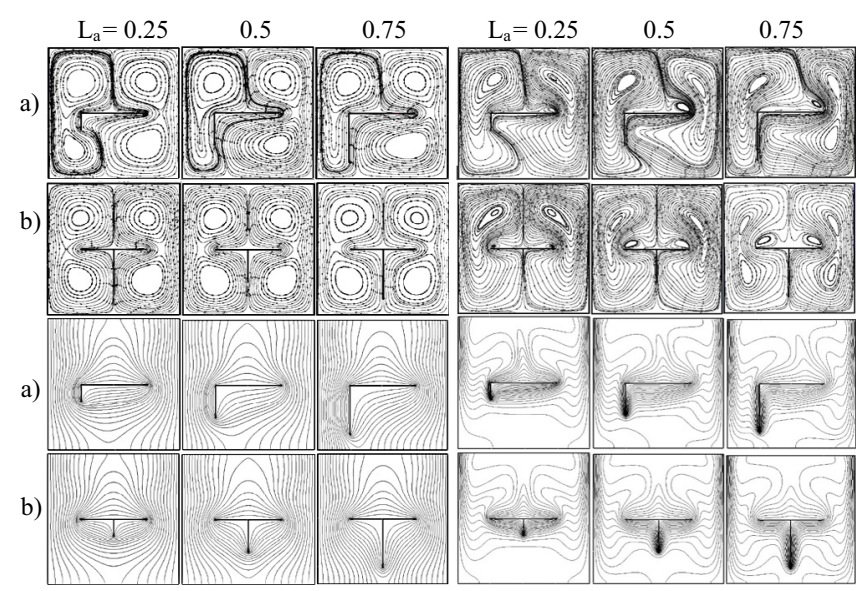

$\mathrm{Ra}=10^{4}$

$\mathrm{Ra}=10^{6}$

Fig. 4. Streamlines and isotherms for a horizontal finned plate oriented facing down (HPFD): $\left(A=0.5 ; A_{1}=0.5\right)$ : (a) $H_{a}=$ 0.25 , (b) $H_{a}=0.5$.

counter-clockwise directions, respectively. For $L_{a}=0.75$, an additional small vortex forms in the bottom left corner $\left(H_{a}=0.25\right)$ or in the upper left corner $\left(H_{a}=0.75\right)$ within the core of the primary left cell. When the position is equal to $0.5\left(H_{a}=0.5\right)$ the left primary cell consists of two co-rotating secondary cells. It is clearly seen that the vortex motion produces a natural convection effect in the area near the cold walls.

As the Rayleigh number increases due to increased transverse temperature gradient, the convection current increases causing significant distortion in the temperature contours. A thin thermal boundary layer appears at the 


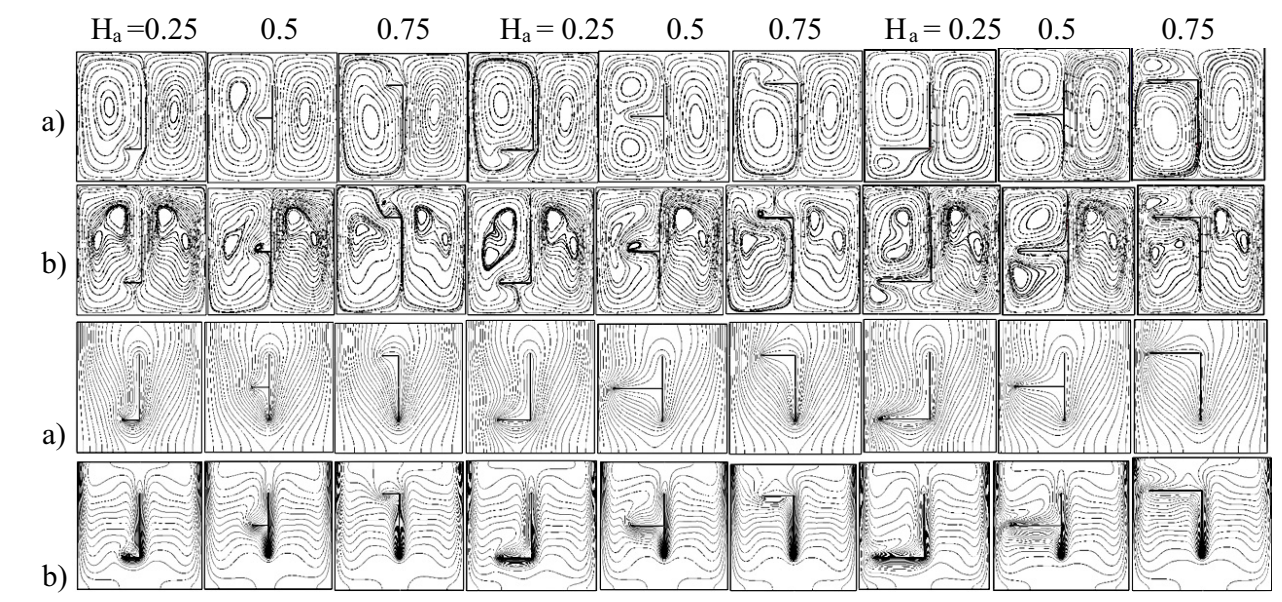

Fig. 5. Streamlines and isotherms for a vertical finned plate oriented facing left (VPFL): $\left(A=0.5 ; A_{2}=0.5\right):(\mathrm{a}) \mathrm{Ra}=10^{4}$, (b) $\mathrm{Ra}=10^{6}$.

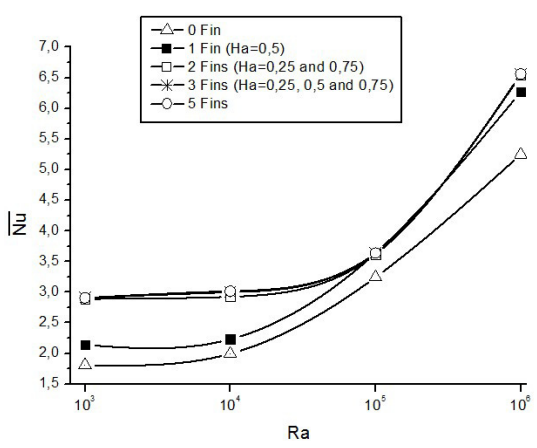

(a)

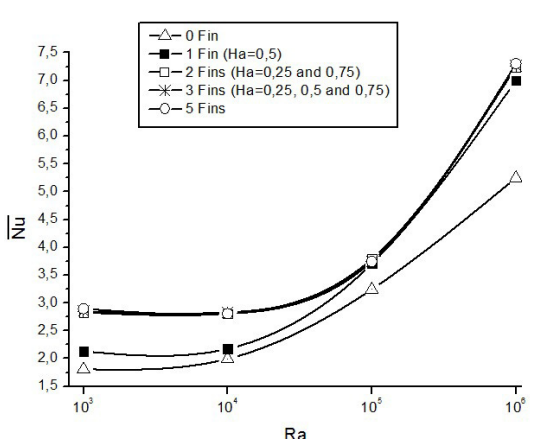

(b)

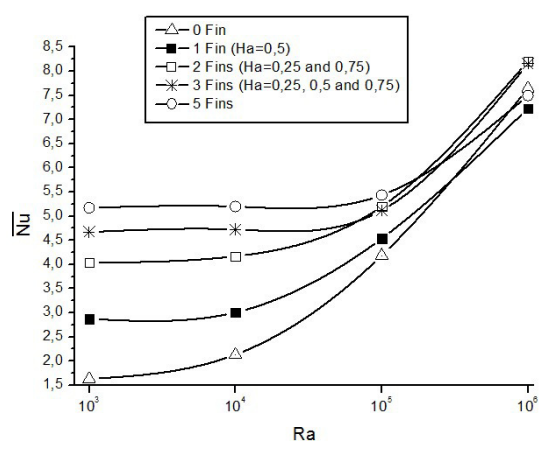

(c)

Fig. 6. Mean Nusselt number for different configurations and $L_{a}=0.75$. (a) Horizontal plate facing up (HPFU), (b) horizontal plate facing down (HPFD) and (c) vertical plate facing left (VPFL).

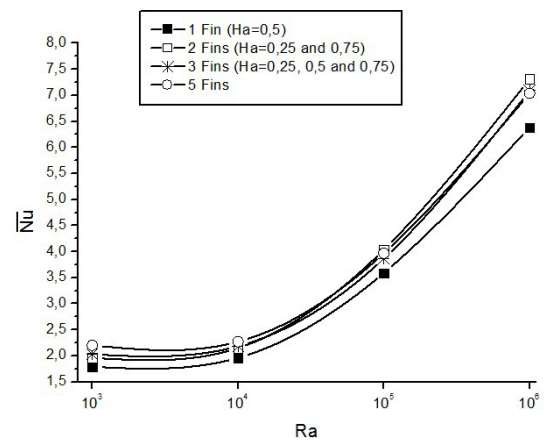

(a)

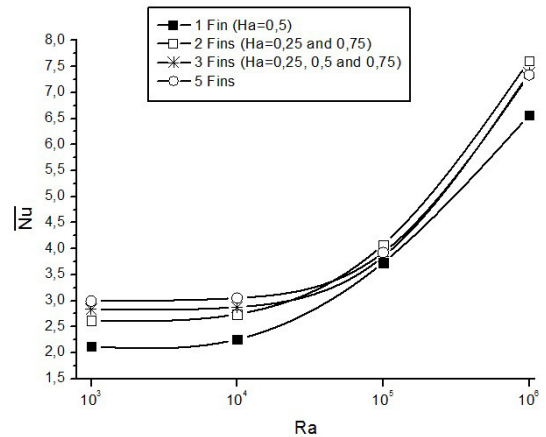

(b)

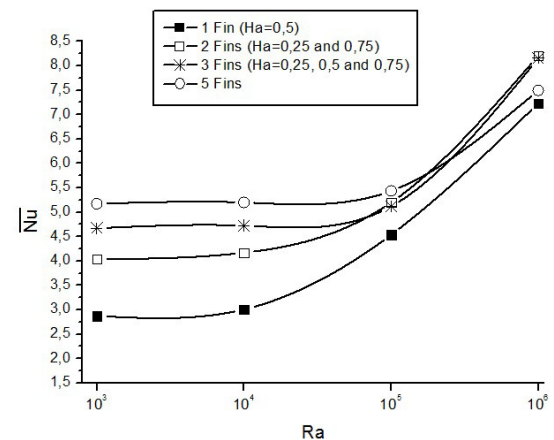

(c)

Fig. 7. Effect of fin length on mean Nusselt number for VPFL case. (a) $L_{a}=0.25$; (b) $L_{a}=0.5$; (c) $L_{a}=0.75$.

tops of the cold walls; this behavior has the tendency to increase the overall wall heat transfer.

\subsection{Effect of Rayleigh number and geometric aspect ratios on heat transfer rate}

Heat transfer rate is presented in term of mean Nusselt number calculated by integrating local Nusselt number distribution along the left cold wall. The dependence of the Nusselt number on fins number for horizontal and vertical configurations, respectively and for different values of fin heights $\left(L_{a}=0.25 ; 0.5\right.$ and 0.75$)$ is shown in Figures 6 and 7 . This allows us to see that the presence of a fin on the plate always increases the wall heat transfer especially in vertical configuration. In general, increasing the Rayleigh number produces higher buoyancy-induced flow within the enclosure and therefore higher Nusselt number. 
For configurations considered in this study, some important observations can be reported. For horizontal oriented plate facing up (HPFU) (Fig. 6a), beyond a Rayleigh number of $10^{5}$ for which convection dominates the number of fins has no significant effect on heat transfer at the cold wall. Whereas, at low regime $\mathrm{Ra}<10^{5}$, beyond two fins $(N f>2)$, the Nusselt number is relatively constant and fins number has no effect on the heat transfer. For horizontal plate oriented facing down (HPFD) (Fig. 6b), as outlined above more than two fins does not induce any improvement in Nusselt number. For $\mathrm{Ra}<10^{5}$ the average Nusselt number is invariant due to the diffusion dominates heat transfer. For a vertical plate oriented facing left (VPFL) (Fig. 6c) an increase in number of fins leads to an improvement of heat transfer as well as the Nusselt number on the left cold wall. This is particularly verified when $\mathrm{Ra} \leq 10^{5}$ (i.e. when the conduction regime dominates). Other hand, for all fins positions, vertical plate configuration (VPFL) allows better heat exchange on the left side wall (i.e. $N f=5$; $\mathrm{Nu}$ passes from 6.5 for HPFU to 8 for VPFL). However as highlighted in Figure 7, the intensity of the heat transfer increases with increasing the length of the fin $\left(L_{a}\right)$ regardless $\mathrm{Ra}$ and $N f$ (number of fins).

\section{Conclusion}

Numerical simulation about natural convection heat transfer inside enclosure with a finned heating element has been carried out with $\operatorname{Pr}=0.71$ and a selected range of Rayleigh number $\left(10^{3}-10^{6}\right)$. The numerical results obtained in terms of Nusselt number, streamlines and isotherms were reported and led to the following conclusions:

- Flow structure and wall heat transfer inside the enclosure depended heavily on the dimensionless parameters $A ; H_{a} ; L_{a}$ and Ra.

- Regardless the number of fins, the Rayleigh number does not entail any significant change on $\mathrm{Nu}$ in diffusion regime, whereas increasing Ra causes stronger Nusselt numbers when convection is the dominant mode.

- For HPFU (HPFD) increasing the number of fins $(N f \geq 2)$ causes minor changes in $\mathrm{Nu}$ whereas it becomes appreciable for VPFL case. At the onset of conduction dominant mode (VPFL), mean Nusselt number increases with increasing the fin number $(\mathrm{Nf})$.

- For all plate positions, results indicate that vertical plate configuration allows better heat exchange compared to the horizontal case (i.e. $L_{a}=0.75$ : HPFU $N u=6.5 ; \operatorname{HPFD} N u=7.25$; VPFL $N u=8.25)$. Moreover, the increase in fin height $\left(0.25 \leq L_{a} \leq 0.75\right)$ causes a continuous increase in the Nusselt number.

- As a finding, for low Ra values it is preferable to use a VPFL (Vertical plate oriented facing left) configuration with $N f=5$ and $L_{a}=0.75$ allowing us a stable thermal gain around $45 \%$. At moderate regime $\left(\mathrm{Ra}=10^{6}\right)$ it is more appropriate to use a configuration with two fins $(N f=2)$.

\section{References}

[1] G. de Vahl Davis, Natural convection of air in a square cavity: a benchmark numerical solution, Int. J. Numer. Methods Fluids 3 (1983) 249-264

[2] S. Mahmud, P.K. Das, N. Hyder, A.K.M. Sadrul Islam, Free convection in an enclosure with vertical wavy walls, Int. J. Thermal Sci. 41 (2002) 440-446

[3] E.H. Ridouane, A. Campo, Free convection performance of circular cavities having two active curved vertical sides and two inactive curved horizontal sides, Appl. Thermal Eng. 26 (2006) 2409-2416

[4] T. Basak, S. Roy, Amit Singh, B. Pandey, Natural convection flow simulation for various angles in a trapezoidal enclosure with linearly heated side wall(s), Int. J. Heat Mass Transfer 52 (2009) 4413-4425

[5] R.S. Kaluri, R. Anandalakshmi, T. Basak, Bejan's heatline analysis of natural convection in right-angled triangular enclosures, Effects of aspect-ratio and thermal boundary conditions, Int. J. Thermal Sci. 49 (2010) 1576-1592

[6] M. Mahmoodi, Numerical simulation of free convection of nanofluid in a square cavity with an inside heater, Int. J. Thermal Sci. 50 (2011) 2161-2175

[7] Z.T. Yu, X. Xu, Y.C. Hu, L.W. Fan, K.F. Cen, Unsteady natural convection heat transfer from a heated horizontal circular cylinder to its air-filled coaxial triangular enclosure, Int. J. Heat Mass Transfer 54 (2011) 1563-1571

[8] A. Sahi, D. Sadaoui, B. Meziani, K. Mansouri, Effects of thermal boundary conditions, surface radiation and aspect ratio on thermal performance in " $\mathrm{T}$ " shallow cavity, Mechanics \& Industry 15 (2014) 557-568

[9] A. Kumar De, A. Dalal, A numerical study of natural convection around a square, horizontal, heated cylinder placed in an enclosure, Int. J. Heat Mass Transfer 49 (2006) 4608-4623

[10] M. Bouafia, O. Daube, Natural convection for large temperature gradients around a square solid body within a rectangular cavity, Int. J. Heat Mass Transfer 50 (2007) 3599-3615

[11] J.M. Lee, M.Y. Ha, H.S. Yoon, Natural convection in a square enclosure with a circular cylinder at different horizontal and diagonal locations, Int. J. Heat Mass Transfer 53 (2010) 5905-5919

[12] S.H. Hussain, A.K. Hussein, Numerical investigation of natural convection phenomena in a uniformly heated circular cylinder immersed in square enclosure filled with air at different vertical locations, Int. Commun. Heat Mass Transfer 37 (2010) 1115-1126

[13] H. Sun, E. Chénier, G. Lauriat, Effect of surface radiation on the breakdown of steady natural convection flows in a square, air-filled cavity containing a centered inner body, Appl. Thermal Eng. 31 (2011) 1252-1262

[14] M. Mahmoodi, S.M. Sebdani, Natural convection in a square cavity containing a nanofluid and an adiabatic square block at the center, Superlattices and Microstructures 52 (2012) 261-275

[15] Y.G. Park, M.Y. Ha, H.S. Yoon, Study on natural convection in a cold square enclosure with a pair of hot horizontal cylinders positioned at different vertical locations, Int. J. Heat Mass Transfer 65 (2013) 696-712

[16] S.H. Tasnim, M.R. Collins, Numerical analysis of heat transfer in a square cavity with a baffle on the hot wall, Int. Commun. Heat Mass transfer 31 (2004) 639-650 
[17] E. Bilgen, Natural convection in cavities with a thin fin on the hot wall, Int. J. Heat Mass Transfer 48 (2005) 3493-3505

[18] H. Oztop, E. Bilgen, Natural convection in differentially heated and partially divided square cavities with internal heat generation, Int. J. Heat Fluid Flow 27 (2006) 466475

[19] A. Mezrhab, M. Jami, C. Abid, M. Bouzidi, P. Lallemand, Lattice-Boltzmann modelling of natural convection in an inclined square enclosure with partitions attached to its cold wall, Int. J. Heat Fluid Flow 27 (2006) 456-465

[20] A. Ben-Nakhi, Ali J. Chamkha, Conjugate natural convection in a square enclosure with inclined thin fin of arbitrary length. Int. J. Thermal Sci. 46 (2007) 467-478

[21] N. Kasayapanand, A computational fluid dynamics modeling of natural convection in finned enclosure under electric field, Appl. Thermal Eng. 29 (2009) 131-141

[22] M. Famouri, K. Hooman, Entropy generation for natural convection by heated partitions in a cavity, Int. Commun. Heat Mass Transfer 35 (2008) 492-502

[23] H.F. Oztop, I. Dagtekin, A. Bahloul, Comparison of position of a heated thin plate located in a cavity for natural convection, Int. Commun. Heat Mass Transfer 31 (2004) $121-132$
[24] S.H. Tasnim, M.R. Collins, Suppressing natural convection in a differentially heated square cavity with an arc shaped baffle, Int. Commun. Heat Mass Transfer 32 (2005) 94-106

[25] Z. Altac, O. Kurtul, Natural convection in tilted rectangular enclosures with a vertically situated hot plate inside, Appl. Thermal Eng. 27 (2007) 1832-1840

[26] A.K. Abdul Hakeem, S. Saravanan, P. Kandaswamy, Buoyancy convection in a square cavity with mutually orthogonal heat generating baffles, Int. J. Heat Fluid Flow 29 (2008) 1164-1173

[27] A.K. Abdul Hakeem, S. Saravanan, P. Kandaswamy, Natural convection in a square cavity due to thermally active plates for different boundary conditions, Comput. Math. Appl. 62 (2011) 491-496

[28] S. Saravanan, C. Sivaraj, Coupled thermal radiation and natural convection heat transfer in a cavity with a heated plate inside, Int. J. Heat Fluid Flow 40 (2013) 54-64

[29] M. Mahmoodi, Numerical simulation of free convection of nanofluid in a square cavity with an inside heater, Int. J. Thermal Sci. 50 (2011) 2161-2175 